\title{
The performance of the computer software and services sector in Argentina: microeconometric evidence on public-sector support programmes
}

\author{
Mariano Pereira, María Florencia Barletta and Gabriel Yoguel
}

\section{Abstract}

This article analyses the impact of public-sector support programmes on the recent performance of the computer software and services sector in Argentina. First, the effect of these programmes on firms' innovation performance is studied, with a propensity score matching technique used to calculate the average treatment effect on treated firms. The results confirm that receiving public funds had a positive impact on the ratio between research and development (R\&D) spending and sales, employment in R\&D and the propensity to introduce new products or processes. The effect of policy intervention on firms' economic performance is then analysed, with an instrumental variables design being used in this case. The results show a positive impact on the propensity to export, export intensity and employment growth.

\section{Keywords}

Informatics, computer programs, industry, innovation, research and development, science and technology policy, industrial promotion, econometric models, Argentina

JEL classification

C210, O320, L860

\section{Authors}

Mariano Pereira is coordinator of the Information, Monitoring and Evaluation Unit (UIME) of the Interdisciplinary Centre for Studies in Science, Technology and Innovation (CIECTI) and a research teaching fellow at the Institute of Industry of General Sarmiento National University (UNGS), Argentina. lic.mpereira@gmail.com

María Florencia Barletta is a research teaching fellow at the Institute of Industry of General Sarmiento National University (UNGS), Argentina. fbarlett@ungs.edu.ar

Gabriel Yoguel is a research teaching fellow at the Institute of Industry of General Sarmiento National University (UNGS), Argentina. gyoguel@ungs.edu.ar 


\section{Introduction}

In the early 2000s, the outlook for the computer software and services sector in Argentina seemed extremely negative. Nobody foresaw that just over a decade later, employment in the sector would outstrip that in the automotive complex (by 8\%) and in several primary sectors (agricultural services), industrial sectors (capital goods, leather and footwear, wood, furniture, iron and steel) and service sectors (electricity, gas and water), and would almost match that in sectors employing far more people in the late 1990s (banking, insurance and real-estate services). A number of published studies made it clear that the problems facing the sector limited its prospects for development. These constraints centred on three areas: (i) commercial capabilities that were too focused on the domestic market, which hampered the potential for developing an industry that could compete externally (López and Ramos, 2008); (ii) workers' limited technological capabilities, which constrained the level of complexity attainable in products and services (Borello and others, 2005), and (iii) the lack of a critical mass of prominent firms with in-house product development capabilities, which limited the scope for identifying successful sectoral profiles (Chudnovsky, López and Melitsko, 2001; López, 2003; Perazzo and others, 1999). Despite these constraints, though, the sector took a very different path. Since the devaluation of the Argentine peso in 2002, computer software and services firms have grown apace, with aggregate employment, sales and exports all rising much faster than in manufacturing industry (Barletta and others, 2013; Maldonado, Morero and Borrastero, 2013).

The main factors behind this performance have been: the increased competitiveness of the Argentine economy since the devaluation of early 2002, greater outsourcing of software development around the world (which dynamized a major segment of computer software and services firms) and other cultural and contextual characteristics favourable to participation in external markets (knowledge of English, time zones and availability of skilled human resources, among others). These factors were supplemented by some local ones, such as strong growth in the domestic market and the high level of capabilities generated in earlier decades at older firms and since the early 2000s in the great majority of the new ones, and by a large range of public programmes to promote quality certification, exports and research and development $(R \& D)$, which propelled innovation efforts. Over the past few years, a number of studies have looked at the determinants of the recent performance of the computer software and services sector in Argentina. However, surprisingly few have analysed the effects of innovation support programmes on the performance of the knowledge-intensive services sector in general and computer software and services in particular (Castro and Jorrat, 2013).

The present article has three specific aims: (i) to evaluate the causal effect of innovation support programmes on firms' innovation and economic performance; (ii) to analyse the existence of spillovers or indirect effects by considering links between beneficiary and non-beneficiary firms forged for the purpose of joint R\&D, and (iii) to evaluate complementarity between instruments, since firms can apply for and receive support from more than one programme.

In accordance with these aims, the present article seeks to answer a number of questions. What role has been played by public-sector innovation support programmes in the innovation behaviour of computer software and services firms? Is it possible to say that sectoral incentive instruments have helped improve firms' economic performance via this more virtuous innovation behaviour? What role, ultimately, has been played by public-sector science and technology policy in the sector's strong performance over the last decade? These questions are answered using a database of 187 computer software and services firms constructed specially to capture the specificities of the sector. Two identification techniques are applied to this database to capture the average treatment effect on the treated among firms in receipt of subsidies, fiscal incentives or both in 2010: (i) propensity score matching (Rosenbaum and Rubin, 1983), and (ii) doubly robust estimations (Tsiatis, 2006; Leon, Tsiatis and Davidian, 2003; Lunceford and Davidian, 2004). 
The article is divided into five sections, including this Introduction. The second section presents the database and the descriptive statistics for the differences between beneficiary and non-beneficiary firms. The third section describes the methodology proposed for capturing the causal effect of receipt of a public-sector benefit. The fourth estimates the causal effect of participating in a public-sector programme on a firm's innovation behaviour and economic performance. The fifth and last section contains the main conclusions of the article.

\section{The database}

The database used for this article was compiled from a survey of firms in the computer software and services sector in 2011. The study received financing from the Carolina Foundation in Spain and assistance with sample design from the Employment and Business Dynamics Observatory of the Ministry of Labour, Employment and Social Security. The sample comprises a total of 189 firms, 2 of which were discarded because their data were incomplete. On average, the firms examined employed about 60 people each and declared annual sales of about 8 million pesos in 2010, with 56\% stating they engaged in some foreign trade. Most of the firms in the sample began trading in the late 1990s, are Argentine in origin (93\%) and operate independently, with just $10 \%$ forming part of a business group (see table 1).

Table 1

Argentina: descriptive statistics for computer software and services firms, 2010

\begin{tabular}{lccccr}
\hline & Observations & Mean & Standard deviation & Minimum & Maximum \\
\hline Employment (number of employees) & 187 & 58 & 14 & 1 & 1500 \\
\hline Sales (millions of pesos) & 187 & 7.9 & 22.7 & 0 & 200 \\
\hline Exports (0 = does not export; $1=$ exports) & 187 & 0.56 & 0.5 & 0 & 1 \\
\hline Starting year & 187 & 1999 & 7 & 1968 & 2010 \\
\hline Part of business group ( $=$ not part; $1=$ part) & 187 & 0.1 & 0.3 & 0 & 1 \\
\hline Foreign ownership (percentages) & 187 & 7.02 & 2.38 & 0 & 100 \\
\hline
\end{tabular}

Source: Prepared by the authors.

To identify treatment status (i.e., whether a firm participated in some public-sector innovation support programme), the database contains a total of four binary variables. The first three indicate receipt of a benefit from the Argentine Technology Fund (FONTAR), the Trust Fund for the Promotion of the Software Industry (FONSOFT) and the Software Industry Promotion Act, respectively, while the fourth indicates participation in any of the three programmes (BENEF). The frequency distribution (see table 2) reveals that $23 \%$ of firms stated they had received a FONTAR benefit in $2010,49 \%$ that they had participated in FONSOFT and 35\% that they were registered for the purposes of the Software Industry Promotion Act. Overall, across all instruments, 65\% received some kind of research, development and innovation (R\&D\&l) benefit.

Table 2

Argentina: participation by computer software and services firms in public programmes, 2010 (Percentages)

\begin{tabular}{lcccc}
\hline & FONTAR & FONSOFT & Software Industry Promotion Act & BENEF \\
\hline Non-beneficiaries & 77.25 & 51.32 & 64.55 & 34.39 \\
\hline Beneficiaries & 22.75 & 48.68 & 35.45 & 65.61 \\
\hline Total & 100 & 100 & 100 & 100 \\
\hline
\end{tabular}

Source: Prepared by the authors. 
The small sample size means that the possible differential effects of the various financing programmes on the innovation and economic behaviour of computer software and services firms cannot be robustly identified. Consequently, all that is estimated is the average treatment effect on the treated of participation in any of the sectoral support programmes (the BENEF variable).

As for control variables, the database makes it possible to design a heterogeneous set of variables that might affect the likelihood of innovation support being received. The number of employees in 2008 was taken as a proxy for firm size. Since the variable presents a skewed distribution, it was incorporated as a logarithm (I_size). The variable constructed to represent firms' age measures the number of years elapsing from the start of trading to 2008, and the bias in its distribution was corrected by employing the logarithmic form once again (I_age). Two variables were incorporated to complete the structural characterization of the sector: a dichotomous indicator for the firm's membership of a business group (ext_own) and another one, also dichotomous, to indicate whether the firm was located in Buenos Aires (bsas). As a proxy for the firm's capacity for absorption (Cohen and Levinthal, 1990), a binary variable indicating the presence of employees with postgraduate qualifications was created (cap_abs). Also incorporated were three variables for aspects of innovation behaviour within firms. The first is a binary variable indicating whether the firm conducts innovation efforts in the form of internal $R \& D$ (internal_r\&d), the second captures the number of links established with other firms for R\&D purposes (link_firms) and the third is the number of links with public institutions such as universities and technology centres declared by the firm (link_publ). ${ }^{1}$ These latter variables can be expected to positively affect the likelihood of receiving a public-sector benefit. In other words, the expectation is, first, that firms making innovation efforts will be more active innovators and will be more likely to apply for and obtain public-sector funding, and, second, that firms forming part of networks (with other firms, universities or technology centres) to supplement their internal capabilities will be more active users of the instruments made available by the public sector to procure financing.

Lastly, the set of result variables encompasses the innovation and economic dimensions of firms' performance. The following four proxy variables are proposed for innovation performance: (i) a binary variable taking the value 1 if the firm introduced a new product or service into the market (inno); (ii) the ratio between the firm's investment in R\&D and its sales (r\&d_share); (iii) the ratio between the number of employees working in R\&D and the total number of employees (emp_r\&d), and (iv) the ratio between sales of the innovative product or service in dollars and the number of people working in the R\&D department (r\&d_product). In relation to firms' economic performance, three aspects are considered: (i) labour productivity, measured by sales per employee (product); (ii) export performance, measured using two indicators: a binary one indicating whether the firm exports (expo_bin) and a continuous one indicating the firm's export coefficient (expo_share), and (iii) employment performance, based on the cumulative rate of employment growth from 2008 to 2010 (emp_grow).

Table 3 presents the descriptive statistics for the sample variables. In the great majority of cases, the average value of the variables differs significantly between firms in the control group and those in the treatment group. For example, firms that received some support from the programmes analysed were characterized by more proactive innovation behaviour, manifested in higher indices of internal R\&D, links with other firms and institutions and absorption capacity. As regards the set of result variables, although the test of means yields significant differences, these cannot be attributed to participation in the public programme. Systematic differences between the two groups relative to the group of covariates suggest that beneficiary firms are substantially different from their peers in the control group, so a direct comparison between them would be biased. The matching technique applied in this article allows a control group with observable characteristics similar to beneficiary firms' to be selected. After this exercise, the differences between the two groups can, subject to certain assumptions, be explained by participation in the public-sector support programme. To avoid spurious correlations, links with the Ministry of Industry and with the National Agency for the Promotion of Science and
Technology (ANPCyT) of the Ministry of Science, Technology and Productive Innovation were not considered. 
Table 3

Differences of means between treated and untreated firms

\begin{tabular}{lcc} 
& \multicolumn{2}{c}{ BENEF } \\
\cline { 2 - 3 } & Difference & $p$-value \\
\hline Covariates & & \\
\hline I_size & 0.31 & 0.13 \\
\hline I_age & 0 & 0.83 \\
\hline ext_own & -3.24 & 0.38 \\
\hline bsas & 0.11 & 0.10 \\
\hline cap_abs & 0.06 & 0.67 \\
\hline internal_r\&d & 0.22 & 0.00 \\
\hline link_firms & 0.12 & 0.35 \\
\hline link_publ & 0.44 & 0.00 \\
\hline Innovation performance & & \\
\hline prod_inno & 25.33 & 0.00 \\
\hline r\&d_share & 3.84 & 0.42 \\
\hline emp_r\&d & 0.04 & 0.78 \\
\hline r\&d_produc & -72.904 & 0.33 \\
\hline Economic performance & & \\
\hline product & 0.15 & 0.38 \\
\hline expo_bin & 0.17 & 0.03 \\
\hline expo_share & 0.26 & 0.00 \\
\hline emp_grow & 0.01 & 0.09 \\
\hline Source:Prepardby the authors & \\
\hline
\end{tabular}

Source: Prepared by the authors.

\section{Methodological framework}

\section{An exploratory approach from the perspective of causal diagrams}

The directed acyclic graphs (DAG) toolkit can be used to show the difficulties attendant on causal inference when the effects of participating in an innovation support programme are evaluated. Formally, a DAG (Pearl, 2000) is a graphic representation of the qualitative assumptions about causal relations that the researcher has in mind. More simply, it is a network composed of nodes (variables), arrows (suggested causal relations) and missing arrows (suggested non-existent causal relations). To this network may be added a set of assumptions and rules that serve to relate the graph rigorously to econometric data and models.

Figure 1 shows the DAG between a firm's (i) participation in a public-sector programme of R\&D financing; (ii) innovation behaviour, and (iii) economic performance. In this diagram, each node represents a variable (or set of variables) with its corresponding distribution function. The arrow indicates the direction of the causal effect between two variables: if the arrow goes from innovation to performance, then what is being suggested is that the latter is causally affected by the former. The utility of this diagram is that it serves to illustrate the difficulties in identifying the causal effect associated with participation in a public-sector programme. 
Figure 1

Acyclic diagram of causal relations

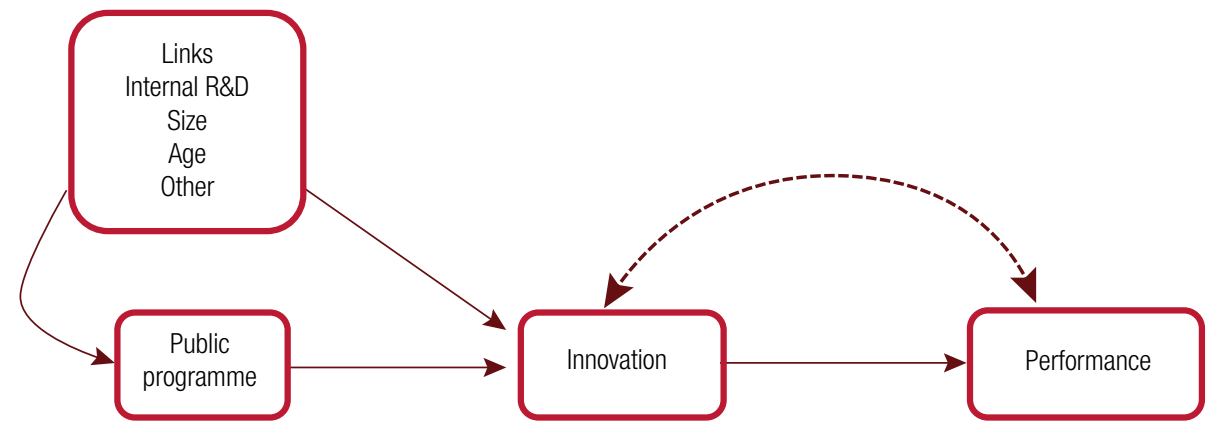

Source: Prepared by the authors.

First of all, we propose a causal relationship between receipt of financing for innovation activities (public programme) and a firm's innovation behaviour (innovation). The diagram indicates a set of covariates affecting both participation in the public programme and the introduction of new products or services. This group of covariates comprises observable factors such as firm size, age, ownership, geographical location, implementation of internal R\&D activities, the presence of employees with postgraduate qualifications and links with other actors (firms, universities or public research centres). With this DAG, the use of an econometric model to estimate the relationship between the programme and innovation will produce a skewed and inconsistent result, since the causal effect may be "confused" with the impact of variations in the set of observable covariates. Consequently, two identification and estimation strategies are proposed to estimate the causal effect of the public programme: (i) a nonparametric estimate based on database balancing using the propensity score for participation in the public programme, and (ii) a doubly robust parametric estimation (Lunceford and Davidian, 2004).

Secondly, the diagram embodies the idea that the relationship between the public programme and a firm's economic performance is mediated by the latter's innovation performance. Consequently, the product of the effect of the innovation programme and the effect of innovation on performance should be used to estimate impact. Since these two variables are determined simultaneously by the presence of unobservable common factors, however (the dotted two-way arrow), the direct estimation proposed above will yield biased and inconsistent results. Thus, to identify this latter effect, an instrumental variables strategy needs to be adopted in which the group of instruments is formed by the set of covariates and participation in the public programme.

\section{Identification strategy: propensity score matching}

The impact evaluation literature offers a varied menu of techniques for estimating the causal effects of a public programme. ${ }^{2}$ They include the following parametric and non-parametric estimation strategies in particular: (i) difference in differences; (ii) selection models; (iii) instrumental variables; (iv) propensity score matching, and (v) regression discontinuity.

In the present case, the structure of the database (presented and analysed in the next section) restricts this large menu. The lack of a cross-sectional and temporal database (micropanel) means that a difference in differences model cannot be estimated. Likewise, because no set of valid instruments is available to capture participation in the support programme, it is impossible to conduct a causal inference study based on instrumental variables methods. The same goes for the possibility of

2 See Heckman, Lalonde and Smith (1999), Imbens and Wooldridge (2009) and, for a broader approach, Morgan and Winship (2007). 
constructing an exclusion equation to estimate a selection model. Thus, the cross-sectional character of the database means that only a propensity score matching technique can be employed.

To begin with, there is assumed to be a variable of interest for firm $i, Y_{i}$ (the decision to innovate or R\&D spending, for example), which can take two values depending on whether the firm participates in a public-sector financing programme. Then, $D_{i}$ is defined as a binary variable taking the value 1 if firm $i$ participated in the programme and 0 if it did not. The variable of interest can thus be defined as follows:

$$
Y_{i}=\left\{\begin{array}{l}
Y_{i 0} \text { if } D_{i}=0 \\
Y_{i 1} \text { if } D_{i}=1
\end{array}\right.
$$

Similarly, the average causal effect of participating in the financing programme can be defined as follows:

$$
E\left(\alpha_{T T}\right)=E\left[\left(Y_{i 1}-Y_{i 0}\right) / D_{i}=1\right]=E\left(Y_{i 1} / D_{i}=1\right)-E\left(Y_{i 0} / D_{i}=1\right)
$$

When the causal effect of a policy is evaluated, responses are sought to a number of questions. What would have happened to the beneficiaries if the programme had not existed? What would have happened to R\&D spending if the programme under examination had not been adopted? From an econometric perspective, this raises a missing data problem. Although we can directly observe $E\left(Y_{i 1} / D_{i}=1\right)$ (the average value of the target variable among firms participating in the programme), this is not the case with $E\left(Y_{i 0} / D_{i}=1\right)$ (the value the target variable would have had if the same firm $i$ had not participated in the programme). It is only possible to see what happened, not what would have happened to the target variable without the programme. This hypothetical situation is known as a counterfactual. Since it cannot be observed, it must be estimated by employing the subgroup of firms that did not participate in the programme: $\widehat{Y_{i 0}}$. Thus, the formula for calculating the average treatment effect on the firms participating in the programme is modified as follows:

$$
E\left(\alpha_{T T}\right)=E\left[\left(Y_{i 1}-\widehat{Y_{i 0}}\right) / D_{i}=1\right]
$$

Since the programme beneficiaries were not assigned randomly, it is not possible to rule out the possibility of selection bias when estimating the impact of $D_{i}$ on $Y_{i}$. Consequently, it cannot be affirmed that $E\left(Y_{i 0} / D_{i}=1\right) \neq E\left(Y_{i 0} / D_{i}=0\right)$, nor can the counterfactual be estimated using the simple average for the firms that did not receive fiscal benefits or subsidies. To solve this problem, recourse may be had to the assumption of conditional independence (Rubin, 1977), according to which both participation in a public programme and the potential outcome of this are statistically independent for firms with the same set of observable characteristics, $X$. Thus, $E\left(Y_{i 0} / D_{i}=1, X\right)=E\left(Y_{i 0} / D_{i}=0, X\right)$ and the differences between the two groups are only attributable to the programme. Given these specifications, the average treatment effect can be estimated as:

$$
E\left(\alpha_{T T}\right)=E\left(Y_{i 1} / D_{i}=1, X=x\right)-E\left(Y_{i 0} / D_{i}=0, X=x\right)
$$

Some important points should be made. Besides the conditional independence assumption, another prerequisite for the consistency of the matching is for there to be adequate overlap between the control group and the group of firms receiving the subsidy. The control group needs to contain at least one unit that is similar enough to each treated firm. In practice, this condition is achieved by restricting the sample to a common support, for which purpose the lower and upper bounds for the propensity score are calculated and observations whose score lies outside these are discarded. 
The exercise of matching each firm that participated in the programme introduces a further problem known as the "curse of dimensionality". The list of observable factors influencing both programme participation and the result studied may be too long, making it almost impossible to carry out separate matching for each individual unit. As the set of observable factors used during the matching procedure grows, the likelihood of finding an exact control drops exponentially. Again, it is very easy to prove in practice that using a relatively small set of factors to apply the matching method yields a set of beneficiaries for which there is no possible match. Rosenbaum and Rubin (1983) suggested matching beneficiaries and non-beneficiaries using their propensity score only (estimate of the conditional likelihood of participating in the programme). This reduces the matching procedure conceived as a multidimensional problem (where the dimension depends on the number of variables in the problem) to a one-dimensional problem. In practice, it is done by means of a maximum likelihood estimation for the probability of participating in the programme in the light of a set of covariates.

However, it is not enough to calculate the propensity score for each firm in the sample. Matching two firms with an identical score is almost impossible, since this is a continuous variable. Accordingly, the econometric literature documents the development of different methods for solving this problem. The present article uses kernel matching: each firm participating in the programme is matched against a weighted average of all the firms in the control group, with the weight they are given being inversely proportional to the distance between the propensity score of the treated firm and the firm in the control group.

Summed up, the basic idea of propensity score matching is to use statistical matching procedures to construct control groups. This methodology corrects for the observable differences between the treatment group (programme beneficiaries) and the control group (non-beneficiaries) by seeking out the individual unit in the non-beneficiary sample (which will form the control group) that best matches each individual unit in the treatment group sample. In this way, the differences between the two groups can only be attributed to participation in the public programme. The main assumption of this methodology is that participation is based on observable characteristics of the individual units. If this is not so, the evaluation results obtained with this methodology will be biased. The source of this distortion lies in the potential correlation between unobservable variables that affect both the individual's decision to participate in the programme and the variable of interest in the evaluation. Table 4 presents a schematic summary of the stages in this method.

Table 4

Steps in propensity score matching

Step 1 Specify and estimate a probit model for programme participation. Generate the probability predicted for each unit in the sample.

Step 2 Restrict the sample to a common support. All firms that have received some fiscal benefit or subsidy and that have

Step 2 a score above or below the maximum or minimum, respectively, are discarded from the control group.

Estimate the average treatment effect on the treated using the kernel method with the following formula:

Step 3

$$
\alpha_{T T}^{\text {kernel }}=\frac{1}{N^{T}} \sum_{i \in T}\left\{Y_{i}^{T}-\frac{\sum_{j \in C} Y_{j}^{C} G\left(\frac{p_{j}-p_{i}}{h_{n}}\right)}{\sum_{k \in C} G\left(\frac{p_{k}-p_{i}}{h_{n}}\right)}\right\}
$$

Where $\mathrm{G}($.$) is a kernel function, h_{n}$ is a bandwidth parameter and $\frac{\sum_{j \in C} Y_{j}^{C} G\left(\frac{p_{j}-p_{i}}{h_{n}}\right)}{\sum_{k \in C} G\left(\frac{p_{k}-p_{i}}{h_{n}}\right)}$

Step 4 Apply bootstrapping to calculate the standard error associated with each average treatment effect on

the treated and check whether the difference of means is statistically different from zero.

Source: Prepared by the authors, on the basis of D. Czarnitzki and C. Lopes-Bento, "Value for money? New microeconometric evidence on public R\&D grants in Flanders", Research Policy, vol. 42, No. 1, Amsterdam, Elsevier, 2013. 


\section{Identification strategy: doubly robust estimation}

Robins and colleagues (Bang and Robins, 2005; Robins, Rotnitzky and Zhao, 1995; Robins, 2000) introduced the concept of doubly robust estimates. This technique requires both the model for estimating each firm's propensity score and the model for estimating the result variable to be used in the same estimator. The estimators calculated in this way are known as semi-parametric efficient estimators. Tsiatis (2006) and Leon, Tsiatis and Davidian (2003) show that these are doubly robust estimators because they yield consistent estimates of the average treatment effect on the treated, provided at least one of the following conditions is met: (i) the propensity score model is properly specified (i.e., $\hat{p}_{i}$ is the true propensity score), or (ii) the regression model relating the result variable with the covariates is properly specified. If both models are well specified, the estimates of the semiparametric estimator will have the least variance. Lunceford and Davidian (2004) propose the following formula to calculate doubly robust estimates:

$$
\hat{\tau}_{D R}=\frac{1}{N} \sum_{i=1}^{N} \frac{A_{i} Y_{i}-\left(A_{i}-\hat{p}_{i}\right) m_{1}\left(\underline{X}_{i}\right)}{\hat{p}_{i}}-\frac{1}{N} \sum_{i=1}^{N} \frac{\left(1-A_{i}\right) Y_{i}+\left(A_{i}-\hat{p}_{i}\right) m_{0}\left(\underline{X}_{i}\right)}{1-\hat{p}_{i}}
$$

Where $\hat{p}_{i}$ is an estimate of the probability of participating in the public programme and $m_{A}=\left(\underline{X}_{i}\right)=E\left(Y_{i} \mid A_{i}=A, \underline{X}_{i}\right)$ for $A=0$ or $A=1$ are the predicted values derived from separate regressions of the result variable as a function of the set of covariates.

\section{Evaluation of the causal effect of programme participation}

\section{The effect on innovation behaviour: using propensity score matching to estimate the average treatment effect on the treated}

As was emphasized in the methodology section, the first step in calculating the average treatment effect on the treated is to balance the sample between beneficiary and non-beneficiary firms on the basis of the observable factors. For this, it is necessary to estimate the probability of a computer software and services firm participating in one of the public programmes analysed in the light of its observable characteristics.

To match beneficiary and non-beneficiary firms, a probit model was used to estimate the probability of participation in some public programme. Table 5 presents the marginal effect of each of the variables proposed on the predicted probability. The joint significance test validates the model presented in all cases and suggests a fairly heterogeneous set of results that varies with the public programme analysed. For example, participation in FONTAR is positively affected by the firm's size in 2008, its internal R\&D activities and its links both to other firms and to public institutions, including universities and technology centres. Where FONSOFT is concerned, the results indicate that the likelihood of receiving the benefit differs significantly by geographical location and is greater the more links the firm has to universities and technology centres, and the more internal R\&D it conducts. The likelihood of receiving fiscal benefits under the Software Industry Promotion Act is positively affected by size and is greater when the firm has R\&D links with other firms. Again, this likelihood is systematically higher for firms that conduct internal R\&D and, paradoxically, lower for those that have staff with postgraduate qualifications. The last model analyses the likelihood of participating in any of 
the programmes. There are found to be significant differences by geographical location, while internal $R \& D$ is associated with a positive impact, as are $R \& D$ links to other firms or public institutions.

Table 5

Marginal effects of the probit model on the participation dummy

\begin{tabular}{lc}
\hline & BENEF \\
\hline I_size & 0.015 \\
\hline I_age & 2676 \\
\hline ext_own & -0.001 \\
\hline bsas & $0.155^{\star}$ \\
\hline cap_abs & -0.025 \\
\hline internal_r\&d & $0.215^{\star \star}$ \\
\hline link_firms & $0.012^{\star \star}$ \\
\hline link_publ & $0.426^{\text {** }}$ \\
\hline Wald chi2(8) & 43295 \\
\hline Prob. $>$ chi2 & 0.0000 \\
\hline No. & 187 \\
\hline
\end{tabular}

Source: Prepared by the authors.

Note: Heteroskedasticity-robust standard errors were calculated. ${ }^{*},{ }^{* *}$ and ${ }^{* * *}$ indicate statistical significance at $10 \%, 5 \%$ and $1 \%$, respectively.

As was pointed out earlier, an important prerequisite is for there to be a control observation with a quite similar propensity score for each firm receiving a benefit (common support restriction). For this, the minimum and maximum values of the propensity score were calculated for the firms in the control group, with the result that four firms in the treatment group that were not matched by similar firms in the control group were discarded and consequently not considered in the matching process. ${ }^{3}$ Since the missing observations are not a substantial part of the sample, the common support restriction does not significantly affect the results. Besides the common support requirement, the position involved in the conditional independence assumption is that the differences between beneficiary and nonbeneficiary firms, conditioned by the propensity score, are only attributable to the public programme being studied. From another angle, this assumption implies that differences between the two groups of firms based on observable factors disappear. Thus, the covariates proposed to explain participation in the public programme are required to be balanced between the two groups. Table 6 presents the $p$-value associated with the test of means and suggests that the null hypothesis that there are no differences between beneficiary and non-beneficiary firms cannot be rejected.

Table 6

Quality of matching: p-value of the test of means

\begin{tabular}{ll}
\hline & BENEF \\
\hline I_size & 0.686 \\
\hline I_age & 0.78 \\
\hline ext_own & 0.818 \\
\hline bsas & 0.775 \\
\hline cap_abs & 0.228 \\
\hline internal_r\&d & 0.712 \\
\hline link_firms & 0.646 \\
\hline link_publ & 0.782 \\
\hline
\end{tabular}

Source: Prepared by the authors.

3 This only applies to FONTAR, since there were no units outside the common support region in the other programmes analysed. 
Despite these results, it would be very unwise to assume that matching quality was good solely on the basis of the test of means. ${ }^{4}$ Accordingly, and in line with Rosenbaum and Rubin (1983), the next step was to estimate the standardized average bias after matching to evaluate its quality. Standardized bias is defined as the difference of means in the two situations (treatment and non-treatment), divided by the square root of the mean of the respective variances. The consensus has set a limit of $10 \%$ to evaluate the quality of matching. Table 7 presents the percentage of bias for each covariate. The criterion is met as a rule, with some one-off exceptions.

Table 7

Quality of matching: percentage of standardized bias

\begin{tabular}{lc}
\hline & BENEF \\
\hline I_size & -5.1 \\
\hline I_age & 3.7 \\
\hline ext_own & 2.3 \\
\hline bsas & -3.7 \\
\hline cap_abs & 7.7 \\
\hline internal_r\&d & -4.2 \\
\hline link_firms & -6.2 \\
\hline link_publ & 3.2 \\
\hline
\end{tabular}

Source: Prepared by the authors.

In conclusion, evaluation of the results of the test of means and the standardized bias values shows that all the covariates proposed are well balanced after matching. The matching can be pronounced successful and the average treatment effect on the treated can now be estimated. If there are statistically significant differences, these can be attributed to the benefit received.

It could be argued that the foregoing results lack robustness owing to the small number of beneficiary firms in the sample for some instruments. For this reason, a fourth estimation is proposed, in which the average treatment effect on the treated is calculated by considering participation in any of the public programmes mentioned. The calculations show that for firms in the computer software and services sector, receipt of some benefit was associated with R\&D spending as a share of sales that was almost 6 percentage points higher on average than it would have been in the absence of State aid. The share of R\&D personnel in firms' staffing totals also increased sharply with participation in public-sector support programmes, with the estimate showing a rise of 11 percentage points. Lastly, estimation of the average treatment effect on the treated revealed that the likelihood of introducing a new product into the market was an average of $20 \%$ greater in firms with benefits than in those without (see table 8).

Table 8

Estimates of the average treatment effect on the treated of programmes overall

\begin{tabular}{lccc}
\hline & No. of beneficiaries & Effect (without matching) & Effect (with matching) \\
\hline prod_inno & 124 & 25.00 & $19.00^{\star *}$ \\
\hline r\&d_share & 124 & 5.28 & $5.45^{*}$ \\
\hline r\&d_produc & 124 & -72.904 & -48.601 \\
\hline emp_r\&d & 124 & 0.04 & $0.11^{* \star}$ \\
\hline
\end{tabular}

Source: Prepared by the authors.

Note: Standard errors were calculated by bootstrapping with 300 repetitions. ${ }^{*},{ }^{*}$ and ${ }^{\star * \star}$ indicate statistical significance at $10 \%, 5 \%$ and $1 \%$, respectively.

\footnotetext{
4 The test of means involves very strong assumptions, such as normal distribution of the variables (which is clearly not met when there are binary or multinomial variables), and is highly sensitive to the amount of data in the sample.
} 
Taken all together, the results show that public-sector instruments supporting the sector helped to configure a group of firms with more dynamic innovation behaviour. In particular, higher $R \& D$ spending went to recruit staff focused on these activities. This set of activities explains why innovation is systematically more likely at firms that have received some public-sector benefit. Despite these substantive results, though, no significant differences were observed in the productivity of R\&D teams (measured as sales of the innovative product per employee on the R\&D team) following receipt of the subsidy. This outcome could be due to the shortness of the period analysed (2008 to 2010), with further time being needed for more dynamic innovation behaviour to translate into improved productivity in the area of R\&D.

\section{The effect on innovation behaviour: using doubly robust estimates to estimate the average treatment effect on the treated}

This section applies an alternative technique to estimate the average effect of participating in a publicsector programme of support for R\&D, known as doubly robust estimates.

First, two alterations are made to the group of variables considered. One is that the treatment variable takes the value 1 if the firm participates in any of the financing programmes studied (FONTAR, FONSOFT or the Software Industry Promotion Act). The other is that the group of result variables considered is restricted to: (i) R\&D spending as a percentage of sales; (ii) personnel employed on R\&D as a percentage of the total, and (iii) introduction of a new product on the market.

Doubly robust estimation is another parametric technique that combines matching based on the propensity score with an econometric model. The model proposes a function for each independent variable, including the covariates affecting the decision to participate in the relevant financing programme and a binary variable for participation in some public programme. The estimation is also restricted to observations belonging to the common support region, and each firm is weighted by its propensity score. The results presented in table 9 bear out the overall significance of the model proposed ( $p$-value of $0 \%$ ), the individual significance of the fiscal benefits or subsidies and the non-significance of the remaining variables. This set of results shows that the estimation of the average treatment effect on the treated is not biased and is consistent, as the selection bias based on observable characteristics is controlled for. It can be seen that the estimates obtained are similar to the results arrived at by nonparametric methods, as detailed in table 8.

Table 9

Doubly robust estimates of the average treatment effect on the treated

\begin{tabular}{lccc}
\hline & R\&D spending & Human resources in R\&D & Product innovation \\
\hline Benefit & $6.003^{*}$ & $0.093^{* *}$ & $0.212^{* *}$ \\
\hline Size & -4552 & -0.167 & -0.055 \\
\hline Age & 483.09 & -5.02 & 6399 \\
\hline Internal R\&D & -3.220 & 0.145 & 0.273 \\
\hline R\&D links & -2498 & -0.038 & 0.013 \\
\hline Links with universities etc. & -4428 & -0.008 & 0.019 \\
\hline Postgraduate staff & 6549 & -0.006 & 0.034 \\
\hline Group & 0.003 & 0 & 0.001 \\
\hline Geographical location & -2236 & -0.058 & -0.089 \\
\hline Intercept & -3639123 & 39097 & -48149 \\
\hline Prob. $>$ chi2 & $2.21 \mathrm{E}-07$ & 0.0101238 & 0.0130124 \\
\hline No. & 43 & 173 & 184 \\
\hline
\end{tabular}

Source: Prepared by the authors.

Note: Robust standard errors were calculated. *,** and ${ }^{* \star \star}$ indicate statistical significance at $10 \%, 5 \%$ and $1 \%$, respectively. 


\section{The effect on firms' economic performance: instrumental variables}

The main purpose of this article is to determine the role of public instruments for R\&D financing on the recent performance of the computer software and services sector. The methodological approach adopted was based on the idea that the effect on a firm's performance was mediated by innovation (see figure 1), and it was explained that because the introduction of a new product on the market was contemporaneous with the economic performance being measured, this causal effect was not being captured. The response proposed was to use an instrumental variables technique involving generation of a localized exogenous variation from variables that are redundant when it comes to explaining a firm's performance but highly correlated with the likelihood of innovation.

Three dimensions were taken into account in estimating firms' performance: (i) labour productivity (measured as sales per employee); (ii) export performance (two indicators are used: a binary one indicating whether the firm exports, and a continuous one indicating the firm's export coefficient), and (iii) employment performance (two variables are used: the total number of employees in 2010 and the cumulative growth rate since 2008). The set of observable factors and public programme participation are used to capture the innovation effect.

Table 10 presents the results of the second stage of the instrumental variables method. The maximum likelihood projection obtained in the previous stage (see table 10) was used as an innovation instrument. The statistical inference confirms that innovation, and thence public programme participation, positively affected firms' performance. In particular, the results show a causal effect on export performance (both the probability of selling to international markets and the export coefficient) and the rate of employment growth. Lastly, no causal effect on labour productivity is captured.

Table 10

The effect of innovation on firms' performance

\begin{tabular}{lcccc}
\hline & Labour productivity & $\begin{array}{l}\text { Exports } \\
\text { (binary) }\end{array}$ & Export coefficient & Employment growth \\
\hline inno_prod & 0.288 & $2.295^{\star \star \star}$ & $1.770^{\star \star}$ & $1.461^{*}$ \\
\hline I_size & $0.172^{\star \star}$ & $0.244^{\star \star \star}$ & $0.170^{\star \star}$ & $-0.139^{\star}$ \\
\hline I_age & -17296 & 9727 & 25563 & $69.928^{\star \star \star}$ \\
\hline ext_own & $-0.010^{\star \star}$ & $0.010^{\star}$ & $0.013^{\star \star *}$ & $0.017^{\star \star \star}$ \\
\hline bsas & 0.195 & -0.137 & -0.16 & 0.051 \\
\hline Intercept & & -75965 & & 39186 \\
\hline chi2 & 12227 & 20228 & 27154 & 0.0000 \\
\hline P & 0.0318 & 0.0011 & 0.0001 & 182 \\
\hline No. & 171 & 188 & 185 &
\end{tabular}

Source: Prepared by the authors.

Note: Robust standard errors were calculated. *,** and ${ }^{* \star *}$ indicate statistical significance at $10 \%, 5 \%$ and $1 \%$, respectively.

\section{Conclusions}

The computer software and services sector in Argentina has performed remarkably well in recent years, becoming one of the most dynamic sectors in the country. Growth figures for domestic sales, exports and employment have been much higher than those for manufacturing and other types of services. Just 15 years ago it was unthinkable that by 2014 the computer software and services sector would be employing more staff than the automotive complex in the aggregate. The present document sets out 
from this context to provide a general characterization of the sector with a view to understanding the factors that determined firms' economic and innovation performance. Broadly speaking, this growth is explained by a varied set of factors associated with the local and global economic context of the past 15 years. Among them, public policy in support of the sector, implemented by national funds such as FONTAR and FONSOFT and underpinned by the Software Industry Promotion Act of 2004, seems to have played an important role.

The descriptive statistics presented in this document show that over half the firms surveyed had access to some type of public-sector benefit. Comparing beneficiary firms with non-beneficiaries reveals that the former have a higher ratio of R\&D investment to sales, more quality certifications and more links to other firms and institutions for the purpose of accessing outside knowledge to supplement their own capabilities. Thus, the evidence found supports the hypothesis that publicsector programmes in support of innovation have helped to configure a group of firms characterized by more dynamic innovation behaviour.

A number of econometric exercises were then carried out to evaluate specifically the role of public programmes in firms' economic and innovation performance. The results bring to light a chain of causal reactions that show, in the first instance, a positive effect accruing to firms from programmes supporting innovation behaviour. In some dimensions, such as the intensity of R\&D spending (whether this is measured as the ratio between spending and sales or the percentage of workers dedicated exclusively to R\&D work), participation in the public programme was followed by a large increase on the levels that would have been achieved in the absence of State intervention. In parallel with this, receipt of funds to supplement R\&D investment was associated with more firms bringing a new product or service on to the market.

It was then shown that, taking the effect on the likelihood of innovation as a yardstick, public programmes in support of the sector were also a determinant of firms' performance in the market. This causal effect proved significant for firms' performance in international markets and in terms of employment, but not for productivity.

Consequently, it can be said that vertical promotion instruments targeted at the computer software and services sector played an important role in its rise after the country's fixed exchangerate regime ended. Public intervention, and particularly industrial and technological policy, is a determinant that is often underestimated in the literature by comparison with exogenous factors, such as competitiveness gains deriving from devaluation, or favourable cultural factors, such as mastery of English or the time zone. This document provides quantitative information which it is hoped will contribute to a greater appreciation of the role of public intervention, particularly when this is conducted with vertically designed instruments like those analysed in this article.

Methodologically, it is important to signal two prior constraints on the impact study that need to be taken into account when the results are evaluated. First, the sample was constructed not for the explicit purpose of conducting an impact assessment, but to analyse the extent to which the technological, organizational and absorption capacity of computer software and services firms and their links to other firms, universities and public institutions supporting the sector explained their economic and innovation performance in recent years. Consequently, the variables used to capture treatment status (e.g., whether or not the firm participated in any of the programmes analysed) did not fully capture this phenomenon. For example, it is not possible to specify the year in which firms accessed these funds (all that is known is that they participated in the programmes between 2008 and 2010), or what the type of instrument was (non-refundable aid, fiscal credit or subsidized credit). Secondly, the cross-sectional nature of the database ruled out the use of evaluation techniques that could yield more precise results, such as a difference in differences study. With these limitations in view, though, the impact assessment design proposed the employment of all techniques that could 
feasibly be used: regression with controls, propensity score matching and doubly robust estimates. The results of the estimations were fairly similar across the different techniques, which is evidence for their robustness. In any event, a very important recommendation regarding the availability of databases for implementing policy evaluation exercises is prompted by these limitations. That is, there is a need for databases designed so that they measure result variables at different points in time and can be cross-matched with information from the register of beneficiary firms, for the treatment and control groups to be specified more accurately.

Lastly, this study raises a number of questions of relevance to the agenda for future research on the role of support instruments in the computer software and services sector. First, there is a need for further analysis of firms accessing more than one innovation support programme. The results presented indicate that programme simultaneity does not affect firms' innovation performance. This suggests a need for greater complementarity between the bodies implementing public policy in order to improve efficiency and avoid incentives overlapping. Since the firms applying for and receiving more than one benefit at a time are likely to be the best performers, there should be an assessment of how far differentiated types of stimulus are required as firms grow. Second, after 15 years' continuous growth in the computer software and services sector, it seems important to have a debate on its future strategic orientation, i.e., to work out a way of specializing in the segments that have been most successful (finance, security and big data, among others) and support the creation of a critical mass of firms that can achieve a more complex specialization profile. Public instruments should be redesigned in the light of this debate with a view to targeting support at these strategic segments.

\section{Bibliography}

Bang, H. and J.M. Robins (2005), "Doubly robust estimation in missing data and causal inference models", Biometrics, vol. 61, No. 4, Washington, D.C., International Biometric Society.

Barletta, F. and others (2013), "Argentina: recent dynamics in the software and IT services industry", CEPAL Review, No. 110 (LC/G.2572-P), Santiago, Economic Commission for Latin America and the Caribbean (ECLAC).

Borello, J. and others (2005), "The technical skills of information technology workers in Argentina", CEPAL Review, N ${ }^{\circ} 8$ (LC/G.2287-P), Santiago, Economic Commission for Latin America and the Caribbean (ECLAC).

Castro, L. and D. Jorrat (2013), "Evaluación de impacto de programas públicos de financiamiento sobre la innovación y la productividad. El caso de los servicios de software e informáticos de la Argentina", Documento de Trabajo, No. 115, Center for the Implementation of Public Policies Promoting Equality and Growth (CIPPEC).

Chudnovsky, D., A. López and S. Melitsko (2001), "El sector de software y servicios informáticos (SSI) en la Argentina: situación actual y perspectivas de desarrollo", Documento de Trabajo, No. 27, Buenos Aires, Research Centre for Industrial Transformation.

Cohen, W.M. and D.A. Levinthal (1990), "Absorptive capacity: a new perspective on learning and innovation", Administrative Science Quarterly, vol. 35, No. 1, SAGE Publications.

Czarnitzki, D. and C. Lopes-Bento (2013), "Value for money? New microeconometric evidence on public R\&D grants in Flanders", Research Policy, vol. 42, No. 1, Amsterdam, Elsevier.

Heckman, J., R. Lalonde and J. Smith (1999), "The economics and econometrics of active labor market programs", Handbook of Labor Economics, vol. 3, O. Ashenfelter and D. Card (eds.), Amsterdam, Elsevier.

Imbens, G.W. and J.M. Wooldridge (2009), "Recent developments in the econometrics of program evaluation", Journal of Economic Literature, vol. 47, No. 1, Nashville, Tennessee, American Economic Association.

Leon, S., A.A. Tsiatis and M. Davidian (2003), "Semiparametric estimation of treatment effect in a pretestposttest study", Biometrics, vol. 59, No. 4, Washington, International Biometric Society.

López, A. (2003), "Innovación y propiedad intelectual en la industria del software y los servicios informáticos. Situación y perspectivas para los países en desarrollo", paper presented at the WIPO-ECLAC Regional Expert Meeting on the National System of Innovation: Intellectual Property, Universities and Enterprises, Santiago. 
López, A. and D. Ramos (2008), La industria de software y servicios informáticos argentina. Tendencias, factores de competitividad y clusters, Buenos Aires, Research Centre for Industrial Transformation.

Lunceford, J.K. and M. Davidian (2004), "Stratification and weighting via the propensity score in estimation of causal treatment effects: a comparative study", Statistics in Medicine, vol. 23, No. 19, Wiley.

Maldonado, M.U., H.A. Morero and C. Borrastero (2013), “'Catching up' en servicios intensivos en conocimiento: el caso de la producción de software y servicios informáticos de Argentina y Brasil”, Revista Iberoamericana de Ciencia, Tecnología y Sociedad, No. 8(24), Buenos Aires, Centro de Estudios sobre Ciencia, Desarrollo y Educación Superior.

Morgan, S. and C. Winship (2007), Counterfactuals and Causal Inference: Methods and Principles for Social Research, Cambridge, Cambridge University Press.

Pearl, J. (2000), Causality: Models, Reasoning, and Inference, Cambridge, Cambridge University Press.

Perazzo, R. and others (1999), "Oportunidades para la producción y exportación argentina de software", Working Paper, No. 9, Buenos Aires, National Agency for Scientific and Technological Promotion.

Robins, J.M. (2000), "Robust estimation in sequentially ignorable missing data and causal inference models", Proceedings of the American Statistical Association Section on Bayesian Statistical Science 1999, Alexandria, American Statistical Association.

Robins, J.M., A. Rotnitzky and L.P. Zhao (1995), "Analysis of semiparametric regression-models for repeated outcomes in the presence of missing data", Journal of the American Statistical Association, vol. 90, No. 429, Taylor \& Francis.

Rosenbaum, P.R. and D.B. Rubin (1983), "The central role of the propensity score observational studies for causal effects", Biometrika, vol. 70, No. 1.

Rubin, D.B. (1977), "Assignment to treatment group on the basis of a covariate", Journal of Educational and Behavioral Statistics, vol. 2, No. 1.

Tsiatis, A. (2006), Semiparametric Theory and Missing Data, Nueva York, Springer. 


\section{Annex A1}

This section briefly summarizes the programmes analysed in the article.

\section{(a) The Software Industry Promotion Act}

In 2004, the Argentine Congress passed the Software Industry Promotion Act (Law No. 25922). This law gave tax breaks to computer software and services firms and created a trust fund called FONSOFT (presented below). For a firm to receive the fiscal benefits established by the law, its main activity must be the creation, design, development, and production and implementation of software systems and associated technical documentation. The software must be wholly developed in Argentina.

Firms also need to do two of the following three things: (i) carry out their own R\&D spending; (ii) hold quality certification, and (iii) export.

The fiscal benefits consist in:

(i) Fiscal stability while the incentive regime is in force (until the end of 2019), with the authorities being debarred from altering the tax system for the sector operated in by firms enrolled in the incentive regime.

(ii) An implicit reduction in social security charges: $70 \%$ of these charges can be credited via payment of other national taxes (except corporation tax).

(iii) Reduction of up to $60 \%$ in the corporation tax payable.

\section{(b) FONSOFT}

As mentioned above, the Trust Fund for the Promotion of the Software Industry (FONSOFT) was created in 2004 under the Software Industry Promotion Act. FONSOFT is a programme that uses subsidies and credits to finance R\&D spending by firms in the sector and start-up costs for firms entering it. The programme is involved at all stages of innovation projects, from formulation and implementation to evaluation of the results. This financing is only available to small and medium-sized enterprises (SMEs) dedicated to the production of software goods and services.

FONSOFT is organized around four instruments: (i) subsidies to firms to improve their quality standards or R\&D spending; (ii) credits to firms to help them begin exporting or consolidate their export activities; (iii) subsidies to business owners to set up new firms, and (iv) matching grants to finance human resources training.

\section{(c) FONTAR}

The Argentine Technology Fund (FONTAR) is another of the funds run by the National Agency for the Promotion of Science and Technology (ANPCyT). ${ }^{5}$ The beneficiaries of FONTAR are innovative firms (particularly SMEs) and public-sector organizations providing technical assistance to the private sector. Funding covers implementation of innovation projects in the following ways: (i) support for

5 ANPCyT is part of the Ministry of Science, Technology and Productive Innovation and was set up in 1996 with the goal of promoting and supporting science and technology. 
implementation of R\&D projects; (ii) technical support for firms looking to draw up projects; (iii) technical and financial advice for firms requiring funding; (iv) financing of the projects selected, and (v) issuance of a certificate of conformity for R\&D teams or departments in accordance with Law No. 23877.

The programme is involved at all stages of the innovation project, from formulation and implementation to evaluation of the results. FONTAR is organized into components, subcomponents and incentive instruments. In practice, firms apply for a particular instrument. Each has its own selection criteria and provides support at different stages of the innovation process.

FONTAR comprises two components: technological innovation in the production sector, and integrated products in production clusters. The former is further divided into three subcomponents that include: (i) technological modernization projects financed with subsidies and loans; (ii) support for technological development at SMEs (including the preparation of patent applications) via subsidies, and (iii) capacity-building for the provision of services to the production sector via refundable loans to non-profit organizations and private institutions. 